\title{
The Role of Organizational Agility in Reinforcing Job Engagement: A Study on Industrial Companies in Egypt
}

\author{
Wageeh A. Nafei ${ }^{1}$ \\ ${ }^{1}$ University of Sadat City, Menoufia, Egypt \\ Correspondence: Wageeh A. Nafei, University of Sadat City, Menoufia, Egypt. E-mail: \\ dr.wageeh1965@yahoo.com \\ Received: August 9, 2015 \\ Accepted: January 19, 2016 \\ Online Published: January 25, 2016 \\ doi: 10.5539/ibr.v9n2p153 \\ URL: http://dx.doi.org/10.5539/ibr.v9n2p153
}

\begin{abstract}
Background: In the current turbulent and highly competitive environment, organizational agility (OA), that is the ability of organizations to quickly sense and respond to environmental changes, is an important determinant of organization success.
\end{abstract}

Purpose: The purpose of this research is to identify the types of OA (sensing agility, decision-making agility and acting agility) and its role in promoting job engagement (JE) of the employees at the Egyptian industrial companies in Sadat city.

Research Design/Methodology: To assess positive OA, refer to (OA Questionnaire, Jaworski \& Kohli, 1993) and JE (JE Questionnaire, Rich et al. (2010) are used). The data of the study was collected from 315 employees at the Egyptian industrial companies in Sadat city. Out of the 372 questionnaires that were distributed to employees at industrial companies in Egypt, 315 usable questionnaires were returned, a response rate of 85\%. Multiple Regression Analysis (MRA) was used to confirm the research hypotheses.

Findings: The researcher has found that the study subjects do agree that OA directly affects the dimensions of JE of the employees at the industrial companies involved in the current study.

Practical implications: This research helps to stimulate scientific research, particularly in terms of testing the model content, as well as studying the study variables and the factors affecting them. In addition, this research pointed to the need for organizations to practice OA in order to be able to meet contemporary intense competition, as this trend is to play an important role in enhancing JE.

Originality/value: This research dealt with OA in terms of its concept and dimensions, in addition to dealing with the role of OA in promoting JE at the Egyptian industrial companies in Sadat City.

Keywords: organizational agility, job engagement

\section{Introduction}

In the beginning of $21^{\text {st }}$ century, the world faced considerable changes in all aspects, especially great changes in the communicational channels. These changes require organizations to revise their strategic priorities and visions (Sharifi \& Zhang, 1999, 2001). The organizational agility (OA) is one of the methods for responding to these changes and revolution factors. The $\mathrm{OA}$ is a new paradigm for engineering competitive organizations and firms.

In the unpredictable and competitive world of today, the organizations must have different competitive features to compete; otherwise, they will move towards annihilation. One of these features that organizations need in the turbulent environments of today is agility. Agility provides the organization with the possibility of quick response and compatibility with environment and allows the organization to improve its efficiency (Yeganegi \& Azar, 2012).

Since human mind capabilities are limited in terms of grasping important changes that take place in the environment surrounding it, so has the current business environment for any organization in the world become complicated and highly dynamic (Zain et al., 2005). Therefore, it has become necessary that organizations in dire need for light movement of human capital be characterized with sensing agility, decision-making, and agility in carrying out work properly. This should be done in a manner which makes them engaged at work devoting all their efforts, feelings and realization in order to achieve the objectives of the organization (Markos \& Sridevi, 2010; Warr \& Inceoglu, 2012). 
Continuous change is increasingly the new normal rather than the exception in contemporary organizations (Brown \& Eisenhardt, 1998). As a result, interest in OA has grown exponentially for practitioners and researchers (Tallon \& Pinsonneault, 2011).

OA has become the topic of interest of both academics and practitioners in recent years. Nine out of ten executives ranked OA as both critical to business success and growing in importance over time in a McKinsey and Company survey (Sull, 2009).

OA plays an important role in the life of the organization as it provides personnel with knowledge, high skills, restructuring and organizational processes, employing new technology (Sherehiy, 2008).

Research on OA is emerging in information systems field (Izza et al., 2008) due to the extensive reliance of contemporary organizations on information, in general, and information system in particular. OA refers to organizations' ability to thrive by sensing and responding to environmental changes which has become critically important nowadays when the business environment is getting highly competitive and turbulent. It is regarded as a key business factor and a potential enabler to organization's competitiveness (Mathiassen \& Pries-Heje, 2006),

This study is structured as follows: Section one is introductory. Section two presents the literature review. Section three presents the research model. Section four presents the research questions and hypotheses. Section five explains the research strategy. Empirical results are provided in section six. Section seven handles the main findings. Finally, section eight presents the research recommendations.

\section{Literature Review}

\subsection{Organizational Agility}

\subsubsection{The Concept of Organizational Agility}

The concept of agility needs to be well grounded in management theory (Yusuf et al., 1999). Early in the 1990s, the new solution for managing a dynamic and changing environment emerged; agility. Agile manufacturing is the ability of surviving and prospering in a competitive environment of continuous and unpredictable change by reacting quickly and effectively to changing markets, driven by customer-defined products and services (Gunasekaran, 1999).

The creators of "agility" concept at the Iacocca Institute, of Lehigh University (USA), defined it as a manufacturing system with capabilities (hard and soft technologies, human resources, educated management, information) to meet the rapidly changing needs of the marketplace (speed, flexibility, customers, competitors, suppliers, infrastructure, responsiveness). Agility is the successful application of competitive bases such as speed, flexibility, innovation, and quality by the means of the integration of reconfigurable resources and best practices of knowledge-rich environment to provide customer-driven products and services in a fast changing environment (Yusuf et al., 1999).

Agility emphasizes speed and flexibility as the primary attributes of an agile organization (Gunasekaran, 1999). An equally important attribute of agility is the effective response to change and uncertainty (Goldman et al., 1995). Some authors state that responding to change in proper ways and exploiting and taking advantages of changes are the main factors of agility (Sharifi \& Zhang, 1999).

Agility refers to the proactive responses to changes (Bessant et al., 2001). Agility refers to the use of changes as inherent opportunities in turbulent environment (Sharifi \& Zhang, 2001). Agility refers to the ability to survive and progress in the variable and unpredictable environment (Dove, 2001).

Organizational flexibility represents an organization's capacity to adjust its internal structures and processes in a predetermined response to changes in the environment. Adaptability underlies the fit of organizational operations to their environment while flexibility emphasizes the readiness of organizational resources and the ease of resource mobilization. The "agility" concept encompasses both flexibility and adaptability. Agility, as a business concept, was coined in a manufacturing context-particularly in relation to flexible manufacturing systems (Christopher \& Towill, 2001).

Agility is a new concept in contemporary administrative thought. One writer has defined the process of agility in terms of the capabilities necessary to achieve light movement in the organization (Sherehiy, 2008).

Agility is the ability to respond to unpredictable changes with quick response and profitability (Erande \& Verma, 2008).

Agility is an organizational ability to react quickly and effectively to an environment which can change radically (Janssen, 2010). 
The concept of agility means rapid, agile, and active movement. Also, agility refers to the ability of rapid and easy movement and rapidly thinking with a thoughtful method. The root or origin of agility is derived from agile production and this is a concept that has been presented during later years. The agile production has been accepted as a successful strategy by producers that prepare them for a considerable performance (Mehrabi et al., 2013).

According to the different definitions of the word agility, the concept of speed and quick response, and also the concepts of group work and common goal regarding the word organization, can be inferred. Agility can be defined as swiftness and quick response of a harmonious group to the changes made by the environment surrounding them in order to reach a goal (Yeganegi \& Azar, 2012).

OA is the organization's ability to respond quickly and effectively to unexpected opportunities, in addition to providing, in advance, solutions that meet potential needs (Nelson \& Harvey, 1995).

$\mathrm{OA}$ is the ability to survive and grow in an unexpected competitive environment of constant change through rapid response to changing markets and through meeting the desires and needs of customers, whether of products or services (Gunasekaran, 1999).

OA is the successful application of the competition rules, such as speed, flexibility, innovation and quality, through the means of integration of resources and the restructuring of best practices in the environment of technical knowledge, through the provision of services or products that meet customers' preferences in light of a rapidly changing environment (Yusuf et al., 1999).

OA is the organization's ability to work comfortably in a quickly and consistently changing and fragmented global market environment, through producing high quality and effective performance (Tsourveloudis \& Valavanis, 2002).

OA enables the organization to carry out a series of specific tasks successfully, in addition to managing the opportunities and risks in the business activities effectively (Ardichvile et al., 2003).

OA makes organizations more responsive to market trends, and faster in terms of the delivery of products and services compared to non-agile ones. OA is composed of three basic dimensions of the sensor agility, decision-making, and agility practice and application (Sambamurthy et al., 2003).

OA is not only "flexible" to cater for predictable changes but also is able to respond and adapt to unpredictable changes quickly and efficiently (Oosterhout et al., 2006). OA can be viewed as the state of organizational performance in terms of flexibility and adaptability and is attainable through organization's activities. In particular, from the process-based perspective, $\mathrm{OA}$ is a set of processes that allow an organization to sense changes and respond efficiently and effectively in timely and cost-effective manner in the internal and external environments. Sensing refers to an organization's ability to detect, capture and interpret organizational opportunities (Seo \& Paz, 2008). Responding represents an organizational ability to mobilize and transform resources to react to the opportunities that it senses (Gattiker et al., 2005; Oosterhout et al., 2006). These two capabilities must be aligned to optimally obtain OA (Overby et al., 2006).

$\mathrm{OA}$ is the organizational capacity to sensor response successfully to the opportunities and threats in the market in a timely manner (Overby et al., 2006).

OA is a proactive management strategy that aims at maintaining the organization's resources and achieving the desires of customers in a timely manner (Hitt et al., 2007).

The concept of OA is derived from performance characteristics of an agile organization and is rooted in two related concepts-"organizational adaptability" and "organizational flexibility". Organizational adaptability focuses on how an organization's form, structure, and degree of formalization influence its ability to quickly adapt to its business environment (Sherehiy et al., 2007).

OA consists of several key elements. They are (1) speed and flexibility, (2) responding to changes in the surrounding environment, (3) high quality products, (4) products and services of accurate information, (5) interacting with social issues and the environment, (6) different technologies collecting, and (7) internal integration inside the institutions and among each other (Sherehiy, 2008).

$\mathrm{OA}$ is the process of arrangement, and abolition of business units, markets and industries to re-focus on differentiated core capabilities (Hill \& Jones, 2009). OA is a package of ideas that aims at continuous improvement, flat organizational structures, work teams, stopping waste or loss, efficient use of resources, and managing the chain of preparation. Japanese companies have adopted the concept of OA in terms of reducing costs through the removal of waste (David, 2009). 
OA is a construction of three basic elements. They are (1) sensing agility, (2) decision-making, and (3) acting using agility and its application (Pavlou \& El Sawy, 2010). OA quickly meets customer requests, offers new products, and gets on strategic alliances or gets rid of them. This means that organizations are in an urgent need of strategic alliances in order to solve the problems of its customers, rather than providing products or one service. The fundamental reason behind the necessity of OA is searching for the core capabilities, on the one hand, and identifying the business environment and capturing opportunities, on the other hand (McCarthy et al., 2010).

$\mathrm{OA}$ is the manufacturing system for physical and non-physical technology, human resources, educated management and information in order to meet the rapidly changing needs of the market in a manner that achieves the desires and needs of the customers in time (Park, 2011).

In light of this, the researcher does identify OA as the organization's ability to achieve its objectives, through the development of its products increasing knowledge of its human resources, effecting the development of the organization and lightening its movement in a rapidly changing environment.

\subsubsection{Dimensions of Organizational Agility}

The dimensions of the $\mathrm{OA}$ are three main types. They are sensing agility, decision-making agility and acting agility (Park, 2011).

\subsubsection{Sensing Agility}

Sensing agility is the organizational capacity to inspect and monitor events and changes in the surrounding environment (customer preferences changes, the movements of the new competitors, new technology) in a timely manner (Park, 2011).

The task of sensing means the strategic monitoring of environmental events that could have an impact on organizational strategy, competitive work, and future performance, including several activities such as access to information related to the events which show environmental change, on the one hand, and getting rid of the trivial information, on the other hand in light of predetermined foundations and rules (El-Sawy, 1985). This task is related to decision-making and its execution (Daft \& Weick, 1984; Dutton \& Duncan, 1987). It is interested in organizational adaptation to change in the surrounding environment (Smircich \& Stubbart, 1985).

\subsubsection{Decision-Making Agility}

Decision-making agility process is the ability to collect, accumulate, restructure and evaluate relevant information according to a variety of sources to explain the implications of the business without delay, and to identify opportunities and threats based on the interpretation of events, along with the development of action plans, which direct the reconfiguration of resources and the development of new competitive procedures (Park, 2011).

Decision-making task consists of several interrelated activities, which explain many events and identify opportunities and threats in the surrounding environment. The task of decision-making focuses on collecting information from multiple and diverse sources in order to understand the implications of their work (Thomas et al., 1993). The task of decision-making seeks to capture the utmost opportunities and minimize the impact of threats on the life of the organization (Houghton et al., 2004).

\subsubsection{Acting Agility/Practicing}

The acting task consists of a set of activities for re-assembling organizational resources and modifying business processes on the basis of the principles of work resulting from the task of decision-making in order to address the change that occurs in the surrounding environment (Eisenhardt \& Martin, 2000).

Organizations can change the business processes by various procedures and resources, redesigning the organizational structure of the organization (Dutton \& Duncan, 1987; Thomas et al., 1993).

The three-dimensions of OA can be explained through the following table (Park, 2011).

Table 1 . The dimension of organizational agility

\begin{tabular}{cl}
\hline Dimensions of OA & \multicolumn{1}{c}{ Clarification of Dimensions } \\
\hline Sensing Agility & Detecting and attracting important business at one time \\
Decision-Making Agility & $\begin{array}{l}\text { Interpreting events, identifying opportunities and threats and taking the actual plans in time } \\
\text { Reshaping organizational resources drastically and modifying business processes and the provision } \\
\text { of services or new products to market in time }\end{array}$ \\
Acting Agility &
\end{tabular}

Source: Park, (2011). The Dynamics of Opportunity and threat Management in Turbulent Environments: The Role Information Technologies, PhD Dissertation. 


\subsection{Job Engagement}

\subsubsection{The Concept of Job Engagement}

Job Engagement (JE) is the emotional link between the employee and the organization, in which he works (Joshi \& Sodhi, 2011).

JE means that employees do what they are told and adapt their work according to job description and in light of the traditional work environment (Frese, 2008).

$\mathrm{JE}$ is the involvement and enthusiasm of the employee to the organization in terms of being ready to devote more effort and innovation in cooperation with the rest of his colleagues, and adapting, effectively, to the changes in the surrounding environment under the contemporary organizational environment characterized by global pressures, intensive customers' demands, low supervision, growing technology, and increasing need for teamwork and communication (Griffin et al., 2008).

$\mathrm{JE}$ is the internal merging of the individual to work, or the psychological congruence and responding to work, something which will affect the individual self-achievement or his commitment to work (Kanungo, 1982).

JE means that the individual likes to do or interested in the work he is associated with, since individuals who love their jobs are working with more productivity and efficacy (Pollock, 1997).

JE represents the degree to which the individual merges with the job he exercises by sensing its importance, so that $\mathrm{JE}$ is associated with both the mental and emotional aspects (Riipinen, 1997).

JE means that the employee is aware of the nature of work in the organization, and working closely with co-workers in order to improve the functionality for the benefit of the organization (Bevan et al., 1997).

There are three basic elements of JE. They are (1) work as the primary interest of man's life, (2) active participation in labor, (3) performance as the basis of self-realization, and (4) performance association with self-conception (Rasmey et al., 1995).

$\mathrm{JE}$ is the commitment and communication of the employee to the job and the organization to which he works (Sweem, 2008).

There are three key aspects to encourage the employee engagement which are (1) workers' experience and their psychological and personal affairs, (2) employers and their ability to create the conditions that encourage employees' engagement and (3) interaction among employees at all the administrative levels of the organization (Tiwar, 2011).

In light of this, the research identifies JE as the positive feeling of the employee towards the organization to which he works in a way that contributes in a high degree in achieving their goals and values.

\subsubsection{Dimensions of Job Engagement}

There are three main dimensions of JE. They are as follows (Rich et al., 2010).

\subsubsection{Cognitive Engagement}

Cognitive engagement means that individuals are fully engaged in exercising the tasks they are assigned with (Rothbard, 2001). Engaged individuals focus intensely on the task given to them within the organization (Rich et al., 2010).

\subsubsection{Emotional Engagement}

Emotional engagement means the existence of a strong relationship between emotions, thoughts, and feelings of the individual and the organization, to which he works (Kahn, 1990). This increases feelings of enthusiasm and pride of the individual towards the organization (Rich et al., 2010).

\subsubsection{Physical Engagement}

Physical engagement means directing man's physical energies towards the completion of a specific task in a way that contributes to achieving the organization's objectives efficiently and effectively (Rich et al., 2010).

\section{Research Model}

The proposed comprehensive conceptual model is presented in Figure 1. The diagram below shows that there is one independent variable of OA. There is one dependent variable of JE. It shows the rational links among the variables. The research model is as shown in the following figure. 


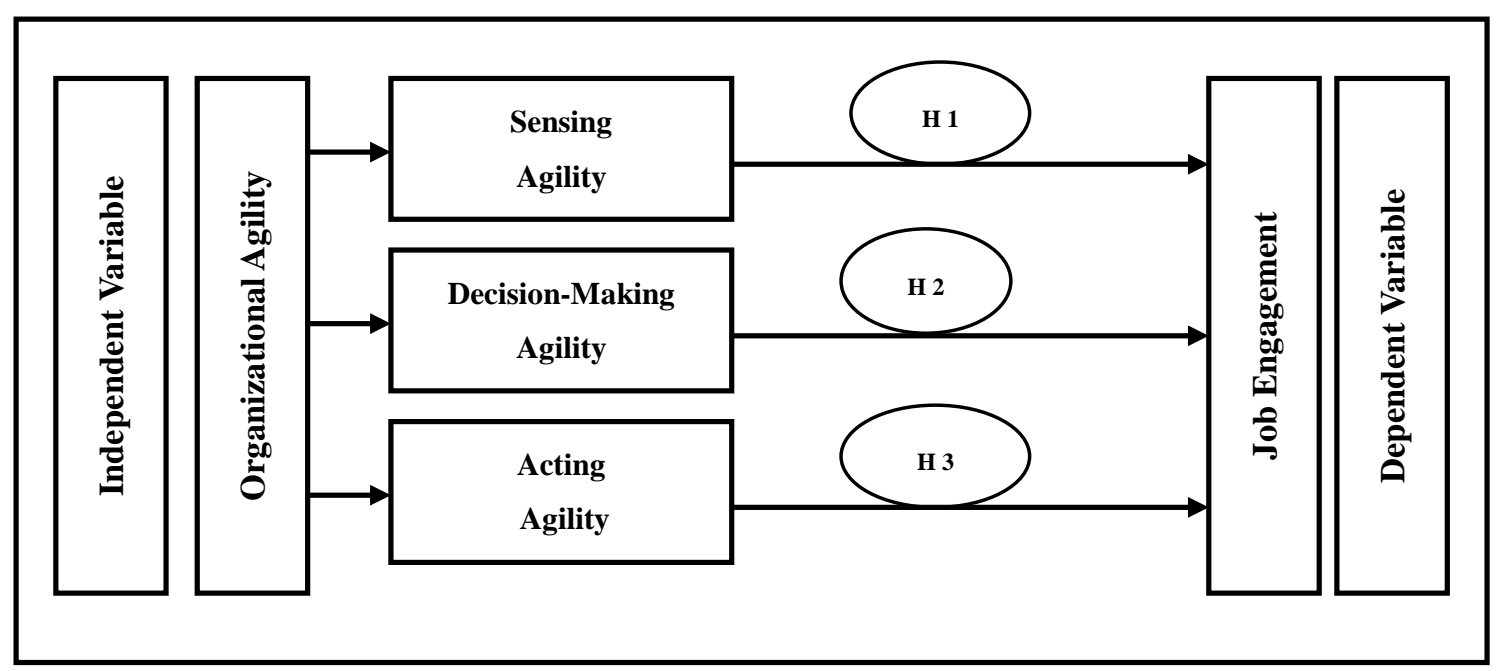

Figure 1. Proposed comprehensive conceptual model

The research framework suggests that OA has an impact on JE. OA as measured consists of sensing agility, decision-making agility and acting agility (Jaworski \& Kohli, 1993). JE is measured in terms of cognitive engagement, emotional engagement, and physical engagement (Rich et al., 2010).

\section{Research Questions and Hypotheses}

The researcher found the research problem through two sources. The first source is to be found in previous studies, and it turns out that there is a lack in the number of literature reviews that dealt with the analysis of the relationship between OA and JE at the Egyptian industrial companies in Sadat City. This called for the researcher to test this relationship in the Egyptian environment. The second source is the pilot study, which was conducted in an interview with (30) employees in order to identify the relationship between OA and JE. The researcher found through the pilot study several indicators; notably the important and vital role that could be played by OA in reinforcing JE at the Egyptian industrial companies in Sadat City. As a result of the discussions given above, the research questions are as follows:

Q1: What is the nature and extent of the relationship between OA (sensing agility) and JE at the Egyptian industrial companies in Sadat City.

Q2: What is the nature of the relationship between OA (decision-making agility) and JE at the Egyptian industrial companies in Sadat City.

Q3: What is the extent of the relationship between OA (acting agility) and JE at the Egyptian industrial companies in Sadat City.

The following hypotheses were developed to test if there is significant correlation between OA and JE.

H1: OA (sensing agility) of employees has no statistically significant effect on JE at the Egyptian industrial companies in Sadat City.

H2: OA (decision-making agility) of employees has no statistically significant impact on JE at the Egyptian industrial companies in Sadat City.

H3: OA (acting agility) of employees has no statistically significant influence on JE at the Egyptian industrial companies in Sadat City.

\section{Research Strategy}

\subsection{Population and Sample}

The population of the study included all employees at the Egyptian industrial companies in Sadat City. The total population is 11550 employees. Determination of respondent sample size was calculated using the formula (Daniel, 1999) as follows:

$$
\mathrm{n}=\frac{N \times(Z)^{2} \times P(1-P)}{d^{2}(N-1)+(Z)^{2} \times P(1-P)}
$$


The number of samples obtained by 372 employees at the Egyptian industrial companies in Sadat City is presented in Table 2.

Table 2. Distribution of the sample size

\begin{tabular}{|c|c|c|c|}
\hline Industrial Companies & Employees & Percentage & Sample Size \\
\hline 1. Ezz Company for Reinforcement Steel & 2100 & $18.2 \%$ & $372 \times 18.2 \%=68$ \\
\hline 2. Arab Company for Steel (Arco Steel) & 750 & $6.5 \%$ & $372 \times 6.50 \%=24$ \\
\hline 3. Horizon for Investment (Geraneto) & 1200 & $10.4 \%$ & $372 \times 10.4 \%=39$ \\
\hline 4. Egyptian-American Steel Company (Bishan) & 3300 & $28.6 \%$ & $372 \times 28.6 \%=106$ \\
\hline 5. Al Gawhara for Ceramics & 2700 & $23.4 \%$ & $372 \times 23.4 \%=87$ \\
\hline 6. Egyptian Group for Investments (Prima) & 1500 & $12.9 \%$ & $372 \times 12.9 \%=48$ \\
\hline Total & 11550 & $100 \%$ & $372 \times 100 \%=372$ \\
\hline
\end{tabular}

Source: Personnel Department at Industrial Companies, Sadat City, Egypt, 2013.

Table 3. Demographic variables frequency distributions

\begin{tabular}{lccc}
\hline \multicolumn{1}{c}{ Demographic Variables } & Category & Frequency & Percentage \\
\hline \multirow{3}{*}{ 1-Sex } & Male & 235 & $74.6 \%$ \\
& Female & 80 & $25.4 \%$ \\
& Total & $\mathbf{3 1 5}$ & $\mathbf{1 0 0 \%}$ \\
& Single & 120 & $38.1 \%$ \\
2-Marital Status & Married & 195 & $68.9 \%$ \\
& Total & $\mathbf{3 1 5}$ & $\mathbf{1 0 0 \%}$ \\
& Under 30 & 110 & $34.9 \%$ \\
3-Age & From 30 to 45 & 155 & $49.2 \%$ \\
& Above 45 & 50 & $15.9 \%$ \\
& Total & $\mathbf{3 1 5}$ & $\mathbf{1 0 0 \%}$ \\
& Secondary school & 100 & $31.7 \%$ \\
4-Educational Level & University & 170 & $54.0 \%$ \\
& Post Graduate & 45 & $14.3 \%$ \\
& Total & $\mathbf{3 1 5}$ & $\mathbf{1 0 0 \%}$ \\
& Less than 5 years & 60 & $19.0 \%$ \\
5-Period of Experience & From 5 to 10 & 215 & $68.3 \%$ \\
& More than 10 & 40 & $12.7 \%$ \\
& Total & $\mathbf{3 1 5}$ & $\mathbf{1 0 0 \%}$ \\
\hline
\end{tabular}

\subsection{Procedure}

The goal of this study was to identify the relationship between OA and JE at the Egyptian industrial companies in Sadat City. A survey research method was used to collect data. The questionnaire included three questions, relating to OA, JE, and biographical information of employees at the Egyptian industrial companies. Data collection took two months. Survey responses were 85\%, 315 completed surveys out of the 372 distributed.

\subsection{Research Variables and Methods of Measuring}

\subsubsection{Organizational Agility}

The researcher will depend on the scale developed by Jaworski and Kohli (1993) in measuring OA, which has been divided into three elements (sensing agility, decision-making agility and acting agility). The 15 -item scale OA section is based on Jaworski and Kohli (1993). There were three items measuring sensing agility, five items measuring decision-making agility, and seven items measuring acting agility. The survey form is used as the main tool for data collection in measuring OA at the Egyptian industrial companies in Sadat City.

\subsubsection{Job Engagement}

The researcher will depend on the scale developed by (Rich et al., 2010) in measuring JE, which has been divided into three main components (cognitive engagement, emotional engagement and physical engagement). The 18-item scale JE section is based on Rich et al. (2010). There were six items measuring cognitive engagement, six items measuring emotional engagement, and six items measuring physical engagement. The 
survey form has been used as a key tool to collect data to measure JE at the Egyptian industrial companies in Sadat City.

Responses to all items scales were anchored on a five (5) point Likert scale for each statement, which ranges from (5) "full agreement," (4) for "agree," (3) for "neutral," (2) for "disagree," and (1) for "full disagreement."

5.4 Data Analysis and Testing Hypotheses

The researcher has employed the following methods: (1) Cronbach's alpha or ACC, (2) (MRA), and (3) F-test and T-test. All these tests are found in SPSS.

\section{Hypotheses Testing}

Before testing the hypotheses and research questions, descriptive statistics were performed to find out means and standard deviations of OA and JE.

Table 4. The mean and standard deviations of OA and JE

\begin{tabular}{clcc}
\hline Variables & \multicolumn{1}{c}{ The Dimension } & Mean & Standard Deviation \\
\hline \multirow{4}{*}{ OA } & Sensing Agility & 4.1598 & 0.75353 \\
& Decision-Making Agility & 3.6711 & 0.81140 \\
& Acting Agility & 4.0186 & 0.64130 \\
& Total Measurement & $\mathbf{3 . 9 1 9 8}$ & $\mathbf{0 . 6 5 0 1 9}$ \\
& Cognitive Engagement & 3.7852 & 0.87551 \\
JE & Emotional Engagement & 3.5439 & 0.92448 \\
& Physical Engagement & 3.6423 & 0.93685 \\
& Total Measurement & $\mathbf{3 . 6 5 7 1}$ & $\mathbf{0 . 9 0 2 9 9}$ \\
\hline
\end{tabular}

According to Table 4, the first issue examined was the different facets of OA (sensing agility, decision-making agility and acting agility). According to Table 4 , among the various facets of OA, those who responded identified the presence of a sensing agility $(M=4.1598, S D=0.75353)$. This was followed by acting agility $(M=4.0186$, $S D=0.64130)$, and decision-making agility $(M=3.6711, S D=0.81140)$.

The second issue examined was the different facets of JE (cognitive engagement, emotional engagement and physical engagement). Most of the respondents identified the presence of a cognitive engagement $(M=3.7852$, $S D=0.87551)$. This was followed by physical engagement $(M=3.6423, S D=0.93685)$, and emotional engagement $(M=3.5439, S D=0.92448)$.

\subsection{Evaluating Reliability}

Data analysis was conducted. All scales were first subjected to reliability analysis. ACC was used to assess the reliability of the scales. Item analysis indicated that dropping any item from the scales would not significantly raise the alphas.

Table 5. Reliability of OA and JE

\begin{tabular}{clcc}
\hline Variables & \multicolumn{1}{c}{ The Dimension } & Number of Statement & ACC \\
\hline \multirow{4}{*}{ OA } & Sensing Agility & 3 & 0.6651 \\
& Decision-Making Agility & 5 & 0.7718 \\
& Acting Agility & 7 & 0.7867 \\
& Total Measurement & $\mathbf{1 5}$ & $\mathbf{0 . 8 9 3 1}$ \\
& Cognitive Engagement & 6 & 0.9107 \\
JE & Emotional Engagement & 6 & 0.9662 \\
& Physical Engagement & 6 & 0.9501 \\
& Total Measurement & $\mathbf{1 8}$ & $\mathbf{0 . 9 8 1 8}$ \\
\hline
\end{tabular}

To assess the reliability of the data, Cronbach's alpha test was conducted. Table 5 shows the reliability results for OA and JE. All items had alphas above 0.70 and were therefore excellent, according to Langdridge's (2004) criteria.

Regarding Table 5, the 15 items of OA are reliable because the ACC is 0.8931 . Sensing agility, which consists of 3 
items, is reliable because the ACC is 0.6651 . Decision-making agility, which consists of 5 items, is reliable because the ACC is 0.7718 . Furthermore, the acting agility which consists of 7 items, is reliable because the ACC is 0.7867 . Thus, the internal consistency of OA can be acceptable.

According to Table 5, the 18 items of JE are reliable because the ACC is 0.9818 . The cognitive engagement, which consists of 6 items, is reliable because the ACC is 0.9107 . The 6 items related to emotional engagement are reliable because ACC is 0.9662 while the last six-item variable (physical engagement) is reliable because the ACC is 0.9501 . Thus, the reliability of JE can be acceptable.

Accordingly, two scales were defined, OA (15 variables), where ACC represented about 0.8931 , and JE (18 variables), where ACC represented 0.9918.

\subsection{The Correlation among the Research Variables}

Table 6. Means, standard deviations and intercorrelations among variables

\begin{tabular}{ccccc}
\hline Variables & Mean & Std. Deviation & JE & OA \\
\hline Organizational Agility & 3.9198 & 0.65019 & & 1.000 \\
Job Engagement & 3.6571 & 0.90299 & 1.000 & $0.439^{* *}$ \\
\hline
\end{tabular}

Table 6 presents correlation coefficients between the research variables, and the results indicate the presence of significant correlation between variables (OA and JE).

$\mathrm{OA}$ is average $(\mathrm{Mean}=3.9198 ; \mathrm{SD}=0.65019)$ leading to a higher level of $\mathrm{JE}$ for employees (Mean=3.6571; $\mathrm{SD}=0.90299)$.

The table shows the existence of a direct correlation between OA and JE ( $\mathrm{R}=0.439 ; \mathrm{P}<0.01)$; the high level of OA leads to the high level of JE of employees at the Egyptian industrial companies in Sadat City.

\subsection{Organizational Agility and Job Engagement}

The relationship between OA and JE at the Egyptian industrial companies in Sadat City is determined. The hypothesis to be tested is: There is no relationship between OA (Sensing Agility, Decision-Making Agility, and Acting Agility) and JE at the Egyptian industrial companies in Sadat City.

Table 7. Correlation between OA and JE

\begin{tabular}{ccccc}
\hline \multicolumn{2}{c}{ Independent Variables } & Dependent Variable & Pearson Correlation & Sign \\
\hline \multirow{3}{*}{$O A$} & & $0.328^{* *}$ & 0.000 \\
& Sensing Agility & JE & $0.322^{* *}$ & 0.000 \\
& Decision-Making Agility & & $0.483^{* *}$ & 0.000 \\
& Acting Agility & 0.4329 & 0.000 \\
\hline
\end{tabular}

Note. $* *$ Correlation is significant at 0.01 level.

Based on Table 7, correlation between OA (sensing agility) and JE is 0.328 . For OA (decision-making agility) and $\mathrm{JE}$, the value is 0.322 whereas $\mathrm{OA}$ (acting agility) and JE show correlation value of 0.483 . The overall correlation between OA and JE is 0.439 .

\subsection{The Relationship between $O A$ (Sensing Agility) and JE}

Table 8 proves that there is a relationship between OA (Sensing Agility) and JE at a significance level of 0,000. As a result of the value of $\mathrm{R}^{2}$, the 3 independent variables of sensing agility can explain $27.4 \%$ of the total differentiation in JE level. 
Table 8. MRA results for OA (sensing agility) and JE

\begin{tabular}{|c|c|c|c|}
\hline The Variables of OA (Sensing Agility) & Beta & $\mathbf{R}$ & $\mathbf{R}^{2}$ \\
\hline $\begin{array}{l}\text { 1. The organization has been slow in terms of detecting changes } \\
\text { that occur in customer preferences for products. }\end{array}$ & $0.496^{* *}$ & $0.278^{* *}$ & 0.0772 \\
\hline $\begin{array}{l}\text { 2. The organization has been slow in terms of detecting changes } \\
\text { that occur in the movements of competitors. }\end{array}$ & $0.386^{* *}$ & $0.439^{* *}$ & 0.0192 \\
\hline 3. The organization has been slow to detect changes in technology. & $0.349^{* *}$ & $0.095^{* *}$ & 0.0001 \\
\hline - $\mathrm{MCC}$ & & 0.524 & \\
\hline - $\mathrm{DC}$ & & 0.274 & \\
\hline - Calculated F & & 39.207 & \\
\hline - Degree of Freedom & & 3,311 & \\
\hline - Indexed F & & 3.78 & \\
\hline - $\quad$ Level of Significance & & 0.000 & \\
\hline
\end{tabular}

For the results of a structural analysis of the MRA, the direct effect of OA (sensing agility) and JE is obtained. Because MCC is 0.524 , it is concluded that there is enough empirical evidence to reject the null hypothesis.

6.5 The relationship between $O A$ (Decision-Making Agility) and JE

Table 9. MRA results for OA (decision-making agility) and JE

\begin{tabular}{|c|c|c|c|}
\hline The Variables of OA (Decision-Making Agility) & Beta & $\mathbf{R}$ & $\mathbf{R}^{2}$ \\
\hline $\begin{array}{l}\text { 1. The organization analyzes important events concerning customers, } \\
\text { competitors, and technology without any delay. }\end{array}$ & $0.170^{* *}$ & $0.277^{* *}$ & 0.0767 \\
\hline $\begin{array}{l}\text { 2. The organization detects the opportunities and threats to changes in } \\
\text { customers, competitors, and technology in time. }\end{array}$ & $0.123^{* *}$ & $0.188^{* *}$ & 0.0353 \\
\hline $\begin{array}{l}\text { 3. The organization carries out a specific action plan in order to meet } \\
\text { customer needs without any delay. }\end{array}$ & $1.345^{* *}$ & $0.240^{* *}$ & 0.0576 \\
\hline $\begin{array}{l}\text { 4. The organization implements a plan of action in order to respond to } \\
\text { the strategic movements of competitors without delay. }\end{array}$ & $1.270^{* *}$ & $0.219^{* *}$ & 0.0479 \\
\hline $\begin{array}{l}\text { 5. The organization is implementing an action plan on how to use the } \\
\text { new technology without delay. }\end{array}$ & 0.107 & $0.261^{* *}$ & 0.0681 \\
\hline - $\mathrm{MCC}$ & & 0.378 & \\
\hline - $\mathrm{DC}$ & & 0.143 & \\
\hline - Calculated F & & 10.295 & \\
\hline - Degree of Freedom & & 5,309 & \\
\hline - $\quad$ Indexed F & & 3.01 & \\
\hline - $\quad$ Level of Significance & & 0.000 & \\
\hline
\end{tabular}

As Table 9 proves, the MRA resulted in the R of 0.378 . This means that JE has been significantly explained by the 5 independent variables of decision-making agility.

Furthermore, the $\mathrm{R}^{2}$ of 0.143 indicates that the percentage of the variable interprets the whole model, that is, $14.3 \%$. It is evident that the five independent variables justified $14.3 \%$ of the total factors of JE. Hence, $85.7 \%$ are explained by the other factors. Therefore, there is enough empirical evidence to reject the null hypothesis.

\subsection{The relationship between $O A$ (Acting Agility) and $J E$}

Table 10 proves that there is a relationship between OA (Acting Agility) and JE. As a result of the value of $\mathrm{R}^{2}$, the 7 independent variables of acting agility can explain 39.8\% of the total differentiation in JE level.

For the results of a structural analysis of the MRA, the direct effect of OA (acting agility) and JE is obtained. Because MCC is 0.631 , there is enough empirical evidence to reject the null hypothesis. 
Table 10. MRA results for OA (Acting Agility) and JE

\begin{tabular}{lccc}
\hline \multicolumn{1}{c}{ The Variables of OA (Acting Agility) } & Beta & R & $\mathbf{R}^{2}$ \\
\hline 1. The organization can reconfigure its resources in the proper time. & $0.144^{* *}$ & $0.272^{* *}$ & 0.0739 \\
2. The organization can re-adjust operations carried out in a timely manner. & $0.070^{* *}$ & $0.331^{* *}$ & 0.1095 \\
3. The organization can use new technology in the proper time. & $0.300^{* *}$ & $0.420^{* *}$ & 0.1764 \\
4. The organization can introduce new products in the proper time. & $0.260^{* *}$ & $0.509^{* *}$ & 0.2591 \\
5. The organization can change prices quickly in the proper time. & $0.186^{*}$ & $0.278^{* *}$ & 0.0772 \\
6. The organization can change strategic things in the proper time. & $0.221^{* *}$ & $0.439^{* *}$ & 0.1927 \\
7. The organization can solve customers' needs and complaints without delay. & $0.258^{* *}$ & $0.095^{* *}$ & 0.0001 \\
- MCC & & 0.631 & \\
- DC & & 0.398 & 29.025 \\
- Calculated F & & 7,307 \\
- Degree of Freedom & & 2.63 \\
- Indexed F & & & 0.000 \\
- Level of Significance & &
\end{tabular}

Note. $* * \mathrm{P}<.01$.

\section{Research Findings}

The present study on analyzing the relationship between OA (sensing agility, decision-making agility and acting agility) and JE at the Egyptian industrial companies in Sadat City revealed the following results:

1) There is a significant relationship between OA and JE at the Egyptian industrial companies in Sadat City. This is consistent with the finding that the employees who believed their organization had a sensing agility, decisionmaking agility and acting agility were more engaged with their job. OA plays an important role in influencing JE. Also, OA contributes significantly to reinforcing JE.

2) This study concluded that the OA was positively related with JE at the Egyptian industrial companies in Sadat City. Overall findings from this study suggested that OA does affect employees' engagement. Hence, the management at the Egyptian industrial companies in Sadat City should ensure that suitable types of agility be applied in the organization through the encouragement of cooperative teamwork.

3) There is a positive relationship between the types of OA (sensing agility, decision-making agility and acting agility) and JE (cognitive engagement, emotional engagement, and physical engagement) of employees at the Egyptian industrial companies in Sadat City. In other words, OA affects JE.

\section{Research Recommendations}

1) It is necessary to pay attention to the impact of the types of OA on JE for employees at the Egyptian industrial companies in Sadat City and for the purpose of obtaining an effective impact of OA on JE.

2) It is necessary to prioritize the order of the dimensions of OA (sensing agility, decision-making agility and acting agility) in order to achieve the goals of organizations, involved in the current study.

3) Factors that lead to JE (cognitive engagement, emotional engagement, and physical engagement) should be enhanced in accordance with contemporary management trends in a changing environment.

4) Focusing on the strength of the relationship between OA and JE in light of the Egyptian industrial companies in Sadat City in order to achieve the objectives of these organizations.

5) Developing and promoting trust between individuals working in the organization, since the availability of this element is a strategic and incomparable dimension. The dimension of experience is no more sufficient alone to achieve organizational success, but rather creating strategic movement agility and encouraging workers towards working engagement

6) It is important for senior administrations of the organizations under study to form specialized teams and conduct seminars and lectures in order to achieve speed, flexibility, responsiveness and adaptability to work with the basic components of the agile organization.

7) It is necessary to provide data and information base in the organizations under study in a way which helps clarify vision to decision makers as regards personnel engagement in work in order to make strategic decisions, results of which may constitute a change in the future of the organizations of the current study. 


\section{Research Implications}

We can conclude that managers at the Egyptian industrial companies in Sadat City might be able to improve JE through OA (sensing agility, decision-making agility and acting agility). OA also helps employees pay attention to professional standards. JE may exist with the help of top management at the Egyptian industrial companies in Sadat City. This is achieved by taking employees interests into account. Absenteeism and turnover will be lower. Productivity and profitability will be higher.

\section{Limitations and Future Research}

There are some limitations of this study. Firstly, the data was collected from employees in Egypt. Therefore, the generalization of the results should be made with caution. Secondly, the findings may not be generalized to other organizations in Egypt. Thirdly, a small sample size is used.

There are several areas for future research. They are (1) the relationship between OA and OCB, (2) the mediating variables which link OA to OP, (3) similar studies should be undertaken in other organizations in Egypt, (4) more studies should look at a comparative study of another sector such as education and tourism, and (5) future studies should examine the relationship between OA and quality of work life.

\section{Conclusion}

This study attempted to investigate the relationship between OA and JE at the Egyptian industrial companies in Sadat City. The study proved that there is a statistical significant relationship between OA and JE. It revealed that $\mathrm{OA}$ and JE are related.

Managers at the Egyptian industrial companies in Sadat City may make use of the present study. It will highlight types of OA and the impact of OA on JE.

The study findings present valuable understanding for managers at the Egyptian industrial companies in Sadat City regarding how to make companies engaged to enhancing their employees, learning effectiveness, improving professional practices, and reducing turnover.

OA has an impact on JE. Top management of the organizations can enhance the dimensions of OA by developing and encouraging some facets of JE.

The Egyptian industrial companies in Sadat City can increase JE by ensuring OA within their organizations. Research on OA and JE increased over the past decade. However, this rapid growth caused several problems, including the need to better understand the conceptual similarities between various forms of OA and JE, as well as their antecedents and consequences. Overall, this is an important and dynamic field of research, and we are hopeful that this paper will help speed progress in this area by highlighting several key issues that need more attention.

\section{References}

Ardichvili, A., Cardozob, R., \& Rayc, S. (2003). A Theory of Entrepreneurial Opportunity Identification and Development. Journal of Business Venturing, 18, 105. http://dx.doi.org/10.1016/S0883-9026(01)00068-4

Bessant, J., Knowles, D., Francis, D., \& Meredith, S. (2001). Developing the Agile Enterprise, Agile Manufacturing: The $21^{\text {st }}$ Century Competitive Strategy. Elsevier Science.

Bevan, S., Barber, L., \& Robinson, D. (1997). Keeping the best: A practical guide to keeping key employees, Report 337. Brighton: Institute for Employment Studies (IES).

Brown, S., \& Eisenhard, K. (1998). Competing on the Edge. Boston, MA: Harvard Business School Press.

Christopher, M., \& Towill, D. (2001). An Integrated Model for the Design of Agile Supply Chains. International Journal of Physical Distribution \& Logistics Management, 31(4), 235-246. http://dx.doi.org/10.1108/09600030110394914

Daft, L., \& Weick, E. (1984). Toward a Model of Organizations as Interpretive Systems. Academy of Management Review, 9, 284-295.

David, F. (2009). Strategic Management-Concepts and Cases (12th ed.). Prentice-Hill Pearson Education International Inc. U.S.A.

Dove, R. (2001). Responsibility: The language, structure, and culture of the agile enterprise. New York: Wiley.

Dutton, J., \& Duncan, R. (1987). The Creation of Momentum for Change through the Process of Strategic Issue Diagnosis. Strategic Management Journal, 8, 279-295. http://dx.doi.org/10.1002/smj.4250080306

Eisenhardt, M., \& Martin, J. (2000). Dynamic Capabilities: What Are They? Strategic Management Journal, 21, 
1105-1121. http://dx.doi.org/10.1002/1097-0266(200010/11)21:10/11<1105::AID-SMJ133>3.0.CO;2-E

El Sawy, O. (1985). Personal Information Systems for Strategic Scanning in Turbulent Environments: Can the CEO Go Go-Line? MIS Quarterly, 9(1), 53-60. http://dx.doi.org/10.2307/249273

Erande, A., \& Verma, A. (2008). Measuring Agility of Organizations-A Comprehensive Agility Measurement Tool $(C A M T)$. Old Dominion University, Proceedings of The 2008 IAJC-IJME International Conference.

Frese, M., \& Fay, D. (2008). Personal initiative (PI): An active performance concept for work in the $21^{\text {st }}$ Century. In B. M. Staw, \& R. M. Sutton (Eds.), Research in Organizational Behavior (pp. 133-187). Amsterdam: Elsevier Science.

Gattiker, T., Chen, D., \& Goodhue, D. (2005). Agility through Standardization: A Crm/Erp Application. In F. R. Jacobs, \& B. Elliot (Eds.), Strategic Erp Extension and Use (pp. 87-96). Stanford Business Books.

Goldman, S., Nagel, R., \& Preiss, K. (1995). Agile Competitors and Virtual Organizations: Strategies for Enriching the Customer. New York: Van. Nostrand Reinhold.

Griffin, M. A., Parker, S. K., \& Neal, A. (2008). Is behavioral engagement a distinct and useful construct? Industrial and Organizational Psychology, 1, 48-51. http://dx.doi.org/10.1111/j.1754-9434.2007.00007.x

Gunasekaran, A. (1999). Agile Manufacturing: A Framework for Research and Development. International Journal of Production Economics, 62, 87-105. http://dx.doi.org/10.1016/S0925-5273(98)00222-9

Hill, C., \& Jones, G. (2009). Strategic Management, An Integrated approach (13th ed.). Boston: Houghton Mifflin Company.

Hitt, M. A., Hoskisson, E. R., \& Ireland, R. D. (2007). Management of Strategy: Concepts and Cases, South-Western (1st ed.). New York.

Houghton, R., El Sawy, O. A., Gray, P., Donegan, C., \& Joshi, A. (2004). Vigilant Information Systems for Managing Enterprises in Dynamic Supply Chains: Real-Time Dashboards at Western Digital. MIS Quarterly Executive, 3(1), 19-35.

Izza, S., Imache, R., Vincent, L., \& Lounis, Y. (2008). An Approach for the Evaluation of the Agility in the Context

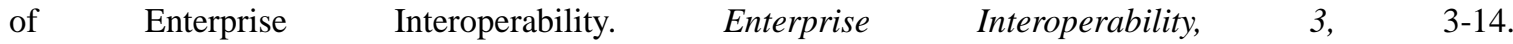
http://dx.doi.org/10.1007/978-1-84800-221-0_1

Janssen, L. (2010). Organizational Agility in an Institutional Context. Supervisors: drs. M.C.P. Nijssen \& Prof. dr. J. Paauwe.

Jaworski, B., \& Kohli, A. (1993). Market Orientation: Antecedents and Consequences. Journal of Marketing, 57(3), 52-70. http://dx.doi.org/10.2307/1251854

Joshi, R., \& Sodhi, J. (2011). Drivers of Employee Engagement in Indian Organizations. The Indian Journal of Industrial Relations, 47(1), 162-182.

Kahn, W. (1990). Psychological Conditions of Personal Engagement and Disengagement at Work.

Kanungo, R. (1982). Measurement of Job and Work Involvement. Journal of Applied psychology, 67(3). 341-349. http://dx.doi.org/10.1037/0021-9010.67.3.341

Markos, S., \& Sridevi, M. (2010). Employee Engagement: The Key to Improving Performance. International Journal of Business and Management, 5(12), 89-96.

Mathiassen, L., \& Pries-Heje, J. (2006). Business Agility and Diffusion of Information Technology. European Journal of Information Systems, 15, 116-119. http://dx.doi.org/10.1057/palgrave.ejis.3000610

McCarthy, I., Lawrence, T., Wixted, B., \& Gordon, B. (2010). A Multidimensional Conceptualization of Environmental Velocity. Academy of Management Review, 35(4), 604-626. http://dx.doi.org/10.5465/AMR.2010.53503029

Mehrabi, S., Siyadat, S., \& Allameh, S. (2013). Examining the Degree of Organizational Agility from Employees' Perspective (Agriculture-Jahad Organization of Shahrekord City). International Journal of Academic Research in Business and Social Sciences, 3(5), 315-323.

Nelson, A., \& Harvey, F. (1995). Technologies for Training and Supporting Your Agile Workforce. In Creating the Agile Organization: Models, Metrics and Pilots 4th Agility Forum Annual Conference.

Oosterhout, M., Waarts, E., \& Van, H. J. (2006). Change Factors Requiring Agility and Implications for It. European Journal of Information Systems, 15(2), 132-145. http://dx.doi.org/10.1057/palgrave.ejis.3000601 
Overby, E., Bharadwaj, A., \& Sambamurthy, V. (2006). Enterprise Agility and the Enabling Role of Information Technology. European Journal of Information Systems, 15(2), 120-131. http://dx.doi.org/10.1057/palgrave.ejis.3000600

Park, Y. (2011). The Dynamics of Opportunity and Threat Management in Turbulent Environments: The Role Information Technologies. Doctor Dissertation.

Pavlou, P., \& El Sawy, O. (2010). The "Third Hand": IT-Enabled Competitive Advantage in Turbulence Through Improvisational Capabilities. Information Systems Research 21(3), 443-471. http://dx.doi.org/10.1287/isre.1100.0280

Pollock, T. (1997). Building Employee's Interest in their work. Automotive Manufacturing \& Production, 109(10), 10.

Ramsey, R., Lassk, F., \& Marshall, G. (1995). A Critical Evaluation of a Measure of Job Involvement : The Use of the Lodahl and Kejner (1965) scale with salespeople. Journal of personal selling \& Sales Management, 15(3), 65-74.

Rich, B., Jeffrey, A., \& Eean, R. (2010). Job Engagement: Antecedents and Effects on Job Performance. Academy of Management Journal, 53(3), 617-635. http://dx.doi.org/10.5465/AMJ.2010.51468988

Riipinen, M. (1997). The Relationship between Job involvement and well-being. The Journal of Psychology, 131(1), 81-89. http://dx.doi.org/10.1080/00223989709603506

Rothbard, N. P. (2001). Enriching or depleting? The dynamics of engagement in work and family roles. Administrative Science Quarterly, 46, 655-684. http://dx.doi.org/10.2307/3094827

Sambamurthy, V., Bharadwaj, A., \& Grover, V. (2003). Shaping Agility through Digital Options: Reconceptualizing the Role of Information Technology in Contemporary Firms. MIS Quarterly, 27(2), 237-263.

Seo, D., \& Paz, A. (2008). Exploring the Dark Side of Is in Achieving Organizational Agility. Communication of the ACM, 51(11), 136-139. http://dx.doi.org/10.1145/1400214.1400242

Sharifi, H., \& Zhang, Z. (2001). Agile Manufacturing in Practice, Application of a Methodology. International $\begin{array}{lllll}\text { Journal of Operations \& Production } & \text { Management, } & 21(5), & \text { 772-794. }\end{array}$ http://dx.doi.org/10.1108/01443570110390462

Sharifi, H., \& Zhang, Z. (1999). A methodology for achieving agility in manufacturing organisations, An introduction. International Journal of Production Economics, 62(1-2), 7-22. http://dx.doi.org/10.1016/S0925-5273(98)00217-5

Sherehiy, B. (2008). Relatioships Between Agility Strategy, Work Organization and Workforce Agility. Doctor Dissertation, University of Louisville.

Sherehiy, B., Karwowski, W., \& Layer, J. (2007). A Review of Enterprise Agility: Concepts, Frameworks, and

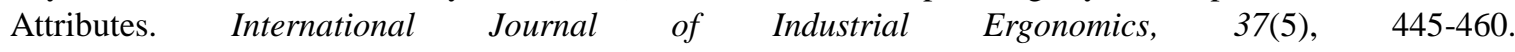
http://dx.doi.org/10.1016/j.ergon.2007.01.007

Smircich, L., \& Stubbart, C. (1985). Strategic Management in an Enacted World. Academy of Management Review, 10(4), 724-736.

Sull, D. (2009). How to Thrive in Turbulent Markets. Harvard Business Review, 87(2), 78-88.

Sweem, S. (2008). Engaging a Talent Management Strategy for the $21^{\text {st }}$ Century: A Case Study of How Talent Management is Defined and Initiated. Midwest Academy of Management Doctoral Student Paper.

Tallon, P. P., \& Pinsonneault, A. (2011). Competing perspectives on the link between strategic information technology alignment and organizational agility: Insights from a mediation model. MIS Quarterly, 35, 463-486.

Thomas, J., Clark, S., \& Gioia, D. (1993). Strategic Sensemaking and Organizational Performance: Linkages among Scanning, Interpretation, Action, and Outcomes. Academy of Management Journal, 36(2), 239-270. http://dx.doi.org/10.2307/256522

Tiwari, S. (2011). Employee Engagement-The Key to Organizational Success. Kolkata: ICOQM-10.

Tsourveloudis, N., \& Valavanis, K. (2002). On the Measurement of Enterprise Agility. Journal of Intelligent \& Robotic Systems, 33(3), 329-342. http://dx.doi.org/10.1023/A:1015096909316 
Warr, P., \& Inceoglu, I. (2012). Job Engagement, Job Satisfaction, and Contrasting Associations With Person-Job Fit. Journal of Occupational Health Psychology, 17(2), 129-138. http://dx.doi.org/10.1037/a0026859

Yeganegi, K., \& Azar, M. (2012). The Effect of IT on Organizational Agility. Proceedings of the 2012 International Conference on Industrial Engineering and Operations Management, Istanbul, Turkey.

Yusuf, Y., Sarhadi, M., \& Gunasekaran, A. (1999). Agile Manufacturing: The Drivers, Concepts and Attributes. $\begin{array}{llll}\text { International Journal of Production } & \text { Economics, } & 62(1-2), & 33-43 .\end{array}$ http://dx.doi.org/10.1016/S0925-5273(98)00219-9

Zain, M., Rose, R., Abdullah, I., \& Masrom, M. (2005). The Relationship between Information Technology Acceptance and Organizational Agility in Malaysia. Information \& Management, 42, 829-839. http://dx.doi.org/10.1016/j.im.2004.09.001

\section{Copyrights}

Copyright for this article is retained by the author(s), with first publication rights granted to the journal.

This is an open-access article distributed under the terms and conditions of the Creative Commons Attribution license (http://creativecommons.org/licenses/by/3.0/). 